Journal of Agricultural Sciences
(Tarim Bilimleri Dergisi)

\title{
Extraction and Physicochemical Characterization of Chitosan from Pink Shrimp (Parapenaeus longirostris) Shell Wastes
}

\author{
Özen Yusuf ÖĞRETMEN ${ }^{a^{*}} \mathbb{D}$, Barış KARSLI ${ }^{a} \mathbb{D}$, Emre ÇAĞLAK $^{a}$ iD \\ ${ }^{a}$ Department of Processing Technology, Faculty of Fisheries, Recep Tayyip Erdogan University, Rize, TURKEY \\ ARTICLE INFO \\ Research Article \\ Corresponding Author: Özen Yusuf ÖĞRETMEN, E-mail: ozenyusuf.ogretmen@erdogan.edu.tr \\ Received: 15 January 2020 / Revised: 29 September 2021 / Accepted: 07 October 2021 / Online: 01 September 2022 \\ Cite this article \\ ÖĞRETMEN Ö Y, KARSLI B, ÇAĞLAK E (2022). Extraction and Physicochemical Characterization of Chitosan from Pink Shrimp (Parapenaeus longirostris) Shell Wastes. Journal of \\ Agricultural Sciences (Tarim Bilimleri Dergisi), 28(3):490-500. DOI: 10.15832/ankutbd.861909
}

\section{ABSTRACT}

This study aimed to evaluate the extract of chitosan obtained from pink shrimp (Parapenaeus longirostris) shell wastes in Balıkesir, the Marmara Sea in Turkey, and to characterize its quality. The physicochemical properties of biopolymer chitosan such as moisture content, solubility, degree of deacetylation (DD), molecular weight (MW), particle size, bulk density, $\mathrm{pH}$, water-binding capacity (WBC), fat-binding capacity (FBC), and color attributes were examined. The obtained chitosan was characterized by Fourier transform infrared spektrofotometer (FT-IR), Dynamic light scattering (DLS), and Thermogravimetric measurements (TG/DTA/DTG). Results indicated that the yield and moisture content of chitosan was $18.82 \%$ and $3.62 \%$, respectively. DD was $81.50 \%$ while solubility was $86.79 \%$. MW of chitosan was found to be $310 \mathrm{kDa}$. The presence of the amino group was confirmed from the FT-IR spectra of the synthesized chitosan. Thermogravimetric measurements showed that chitosan had low thermal stability. SEM analysis revealed that the surface morphologies of chitosan consisted of relatively smooth surface and nanofiber structures. Based on the physicochemical characteristics obtained in the present study, pink shrimp could be a potential source to produce high-quality chitosan for industrial applications.

Keywords: Natural polymer, Autoclave extraction, Waste recycling, Degree of deacetylation, Molecular weight

\section{Introduction}

Chitin is the second most common organic polymer on earth after cellulose (Kucukgulmez et al. 2011) and can be abundantly found in marine invertebrates, crab, shrimp, insects, yeast, and fungi (Samar et al. 2013). In general, dry shrimp waste contains $30-40 \%$ protein, 30-50\% calcium carbonate, and 20-30\% chitin (Ben Seghir \& Benhamza 2017). Chitosan is obtained by the deacetylation of chitin in the solid-state and under alkaline circumstances or by hydrolysis of chitin by chitin deacetylase (Daraghmeh et al. 2011). Chitosan consists of randomly distributed N-acetyl-D-glucosamine and D-glucosamine units (El Knidri et al. 2017) and is widely used in chemical industries, food processing, production of cosmetics, and biomedical and pharmaceutical industries (No et al. 2002). Chitosan and its oligomers have attracted considerable attention because of their antimicrobial, antitumor, and hypocholesterolemic properties (No et al. 2002; Rinaudo 2006). It is generally soluble in aqueous acid solutions such as citric acid, formic acid, acetic acid, lactic acid, etc. but insoluble in water (Karsli et al. 2019). Further, it is non-toxic, biodegradable, and biocompatible (Mourya \& Inamdar 2008). Deacetylation degree (DD) and molecular weight (MW) are critical parameters that strongly affect most of its physicochemical properties and biological activities (El Knidri et al. 2017).

There are many studies showing that chitin and chitosan are prepared by biological and chemical methods. The chemical extraction processes of chitosan have been developed by many researchers by trying different methods (Amoo et al. 2019; Abirami et al. 2021; Hao et al. 2021; Mittal et al. 2021; Vallejo-Dominguez et al. 2021). Traditional isolation of chitin from crustacean shell waste consists of three basic steps: demineralization to remove calcium carbonate and calcium phosphate separation and deproteinization to separate protein and decolorization to removal of pigments. For the production of chitosan, the deacetylation process is applied in addition to these standard process steps used in the production of chitin (VallejoDominguez et al. 2021). Finally, chitin is converted into chitosan that achieved by treatment with concentrated sodium hydroxide solution (between $40-50 \%$ ) at $100{ }^{\circ} \mathrm{C}$ or higher temperature to remove some or all of the acetyl group from the chitin (Galed et al. 2008). There are many studies about chitosan production from shrimp waste in literature (Varun et al. 2017; Ait et al. 2018; del Carmen Borja-Urzola et al. 2020; Dominguez et al. 2021; Mittal et al. 2021). In Turkey, there are some studies relating to the evaluation of these waste. Kucukgulmez et al. (2011) determined the physicochemical properties, yield, moisture and ash contents, degree of deacetylation, molecular weight, water and oil binding capacities, apparent viscosity and color properties of 
chitosan extracted from Metapenaeus stebbingi shells. Tokatlı \& Demirdöven (2018) conducted a study on the optimization and characterization of chitin and chitosan production from shrimp waste. However, the studies on the characterization of chitosan from pink shrimp in Turkey are limited. Only Kucukgulmez et al. (2017) investigated the physicochemical properties of chitosan extracted from the pink shrimp shell and reported that according to the research findings, chitosan production would be beneficial for the economic use of shrimp waste in Turkey.

Total world shrimp production, which reached 5.03 million tons in 2020, is expected to increase to 7.28 million tons by 2025 . However, the amount of pink shrimp caught in Turkey has reported as 1413 tons in 2010 and it has increased to 3851.9 tons in 2019 (TUIK 2020). Approximately 50-60\% of solid wastes generated during shrimp processing are by-products such as head, viscera, and shell (Nirmal et al. 2020). For this reason, recovering these wastes generated during processing will be beneficial for the shrimp processors and the economy of the country. Based on the above explanation, the aim of the present study was to obtain chitosan from pink shrimp (Parapenaeus longirostris) shell wastes and to investigate its physicochemical characteristics properties such as the MW, DD, color, water- and fat-binding capacities, solubility and moisture content.

\section{Material and Methods}

\subsection{Chemicals}

Chemicals used in the chitosan extraction process are hydrochloric acid (ACS reagent, 37\%) and sodium hydroxide (reagent grade, $\geq 98 \%$ ) and they were purchased from Merck, Darmstadt, Germany.

\subsection{Raw material}

Shell wastes from pink shrimp (Parapenaeus longirostris) were collected from a local factory from Balıkesir, Marmara Sea, Turkey, then the samples were packed in plastic bags and stored at $-20^{\circ} \mathrm{C}$ until further use. The shell wastes were separated from other waste materials in a laboratory and stored in a refrigerator at $4{ }^{\circ} \mathrm{C}$. Then, cleaned shrimp shell wastes were washed with distilled water and dried for $24 \mathrm{~h}$ at $60^{\circ} \mathrm{C}$. Approximately $500 \mathrm{~g}$ of dry shrimp shells were used for this study.

\subsection{Extraction of chitosan}

Dried shrimp shell wastes were ground for chitosan extraction and subjected to demineralization, deproteinization, and deacetylation processes.

\subsubsection{Demineralization}

The demineralization process was carried out by modifying the extraction time of the procedure performed by Boudouaia et al. (2019). According to demineralization protocol, shrimp shell powder was treated with $1.35 \mathrm{~N}(5 \% \mathrm{v} / \mathrm{v}) \mathrm{HCl}$ solution (10:1 v/w) at ambient temperature on a magnetic stirrer (Weightlab Instruments, WF-MID1 model) at a speed of $250 \mathrm{rpm}$ for $24 \mathrm{~h}$. The extract was then filtered through Whatman No. 541 filter paper and filtered samples were washed with distilled water until its $\mathrm{pH}$ was neutral.

\subsubsection{Deproteinization}

The deproteinization process was performed by modifying the concentration of $\mathrm{NaOH}$ in the procedure followed by Boudouaia et al. (2019). Deproteinization was performed using $1.75 \mathrm{~N}(7 \% \mathrm{w} / \mathrm{v}) \mathrm{NaOH}$ solution (10:1 v/w) at ambient temperature on a magnetic stirrer at a speed of $250 \mathrm{rpm}$ for $24 \mathrm{~h}$. After deproteinization, the samples were filtered through Whatman No. 541 filter paper and then washed until its $\mathrm{pH}$ reached neutral. After these processes, chitin yield was calculated as $24.44 \%$.

\subsubsection{Deacetylation}

Deacetylation was performed using concentrated $\mathrm{NaOH}$ solution. After deproteinization, the dried samples were heated in an autoclave (Dathan Scientific, WAC-47 model, Seoul-Korea) at $1 \mathrm{~atm}$ pressure (Byun et al. 2013), i.e. $121.1^{\circ} \mathrm{C}$ for 40 min with $50 \% \mathrm{NaOH}$ solution (Sedaghat et al. 2017) and a solid/solvent ratio of 1:20 w/v. After deacetylation, the samples were filtered and washed with distilled water until the $\mathrm{pH}$ was neutral, and then dried in an oven at $60{ }^{\circ} \mathrm{C}$ for $20 \mathrm{~h}$. Figure 1 shows the various steps involved in the chitosan preparation from pink shrimp shell wastes, where major steps such as demineralization, deproteinization, and deacetylation were followed. 


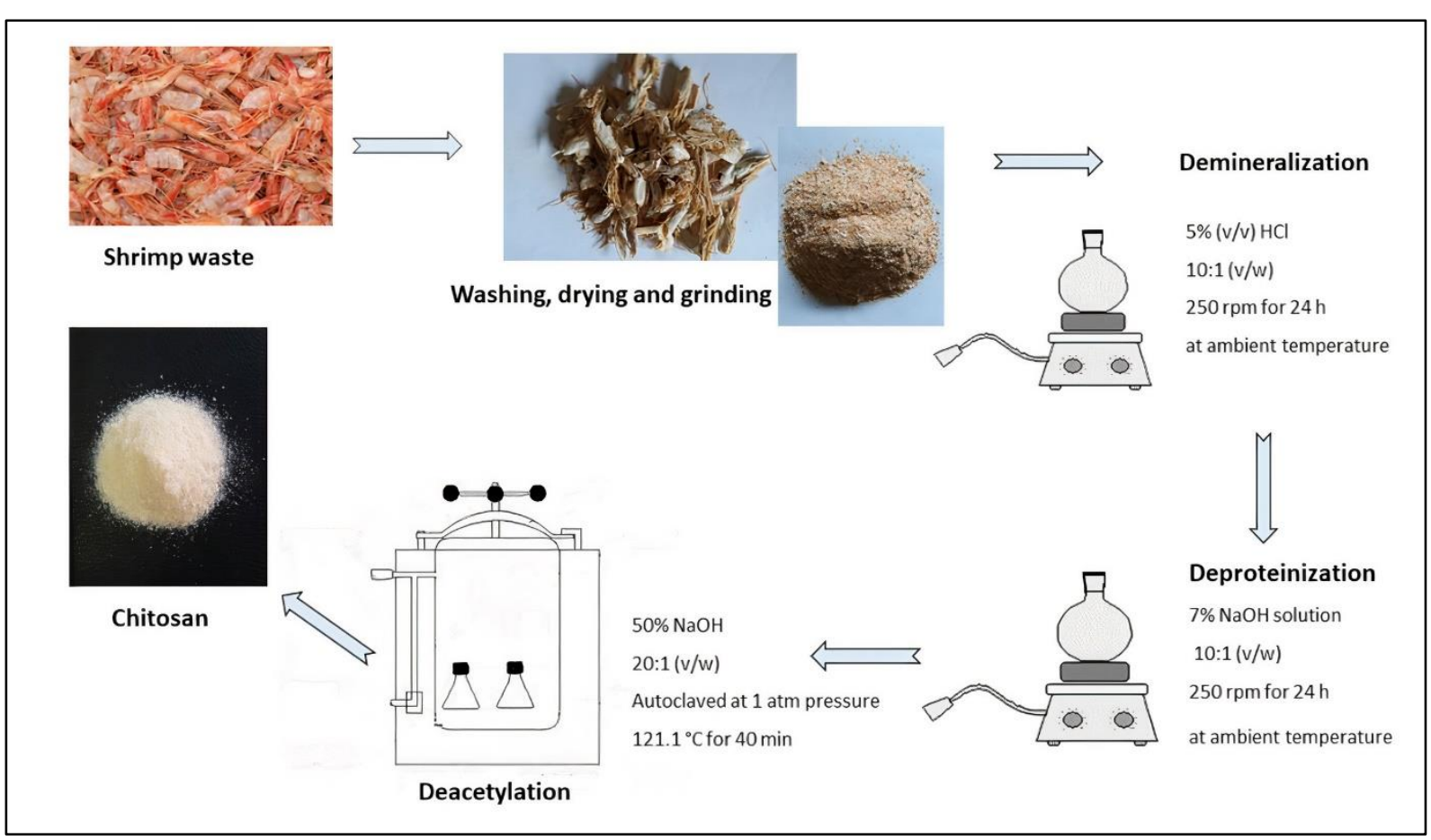

Figure 1- Extraction process of chitosan from pink shrimp shell wastes

\subsection{Characterization of chitosan}

\subsubsection{Determination of yield and moisture content}

Chitosan yield $(\%)$ was determined as the percentage of dried shrimp shells. The moisture contents of the extracted chitosan were analysed by using the standard AOAC method (AOAC 1995).

Chitosan yield $(\%)=[$ dry wt. of obtained chitosan/dry wt. of shrimp shell waste $] \times 100$

\subsubsection{Determination of deacetylation degree}

DD (\%) was determined by FT-IR spectroscopy and calculated using the Domszya \& Roberts (1985) equation:

$$
\mathrm{DD}(\%)=100-\left(\mathrm{A}_{1655} / \mathrm{A}_{3450} \times 100 / 1.33\right)
$$

$\mathrm{A}_{1655}$ : absorbance of the amide-I band at $1655 \mathrm{~cm}^{-1}, \mathrm{~A}_{3450}$ : absorbance of the hydroxyl band at $3450 \mathrm{~cm}^{-1}$. The factor 1.33 denotes the value of the ratio of $\mathrm{A}_{1655} / \mathrm{A}_{3455}$ for $\mathrm{N}$-acetylated chitosan.

\subsubsection{Molecular weight}

The MW of chitosan was determined by the dynamic light scattering (DLS) method. Zetasizer Nano ZSP light scattering system (Malvern Instruments) was used to investigate the chitosan particles (Amiri et al. 2019). DLS was performed at $25^{\circ} \mathrm{C}$ with a laser wavelength of $633 \mathrm{~nm}$ and a scattering detection of $173{ }^{\circ} \mathrm{C}$. Acetic acid solution with a concentration of $0.1 \mathrm{mg} / \mathrm{mL}$ was used for the analysis.

\subsubsection{Water- and fat-binding capacities}

The water-binding capacity (WBC) and fat-binding capacity (FBC) of the chitosan samples were determined according to the method proposed by Knoor (1982). FBC of chitosan extracted from pink shrimp shells was measured using sunflower oil.

\subsubsection{Colorimetric measurement}

Chitosan samples were spread on a petri dish. The colorimetric parameters of the samples were measured using a Konica Minolta colorimeter (model CR-14, Osaka, Japan). The results were denoted as L*, a*, b*, and whiteness index. The whiteness index of the extracted chitosan was calculated based on the following equation (Seo et al. 2007).

Whiteness index $\left.=100-\left[(100-L *)^{2}+(a *)^{2}+(b *)^{2}\right)\right]^{1 / 2}$ 


\subsubsection{Scanning electron microscopic (SEM) analysis}

Morphology and physical state of the surface of chitosan was detected by scanning electron microscopy (Metin et al. 2019). SEM analysis was performed using a JEOL JSM-6610 scanning electron microscope operated at an accelerating voltage of $15 \mathrm{kV}$.

\subsubsection{FT-IR analysis}

The FT-IR spectra of chitosan were analysed using an FT-IR spectrophotometer (PerkinElmer Spectrum 100 Universal ATR Sampling Accessory) at a wave range of 400 to $4000 \mathrm{~cm}^{-1}$ and a resolution of $4 \mathrm{~cm}^{-1}$ using the ATR mode of operation.

\subsubsection{Thermogravimetric analysis}

Thermogravimetric analysis of the chitosan samples (TG/DTA/DTG) was performed using an SII TG/DTG analyzer equipped with A6 6300 under a constant flow of static air atmosphere (heating rate: $10^{\circ} \mathrm{C} / \mathrm{min}$, platinum crucibles, mass: $9.705 \mathrm{mg}$ and temperature range: $25-1000{ }^{\circ} \mathrm{C}$ ) (Hong et al. 2007).

\subsubsection{Solubility, bulk density, particle sizes, and $\mathrm{pH}$ value of chitosan}

For measuring the solubility of chitosan, $0.1 \mathrm{~g}$ of chitosan was dissolved in $10 \mathrm{~mL}$ of $1 \%$ acetic acid for 30 min and then centrifuged at 10,000 x g for $10 \mathrm{~min}$ at room temperature (Nessa et al. 2011). The bulk density of chitosan was measured according to the procedure described by Cho et al. (1998) and calculated into a $25-\mathrm{mL}$ measuring cylinder as $\mathrm{g} / \mathrm{mL}$ of the sample. The particle size of chitosan was determined using a laser scattering size analyzer (Malvern, model 'Mastersizer Hydro 2000 $\mathrm{MU}$ ). The $\mathrm{pH}$ measurement of chitosan solutions (chitosan/distilled water ratio of 1:10 w/v) was carried out using a $\mathrm{pH}$ meter (Hanna, HI 3220, Germany).

\subsection{Statistical analysis}

All analytical determinations were performed in triplicate. The descriptive statistical parameters (mean and standard error) were determined using MS Excel, MS Office 2016 (Microsoft Corporation, Redmond, Washington, USA).

\section{Results and Discussion}

Results of yield, moisture content, DD, WW, WBC, FBC, solubility, and colorimetric parameters of the chitosan samples are provided in Table 1.

Table 1- Physicochemical analysis of the extracted chitosan from shrimp shell waste

\begin{tabular}{|c|c|c|}
\hline Analysis & & Extracted chitosan \\
\hline Yield (\%) & & 18.82 \\
\hline Moisture (\%) & & $3.65 \pm 0.36$ \\
\hline Deacetylation degree (\%) & & 81.50 \\
\hline Molecular weight (kDa) & & 310 \\
\hline Water binding capacity $(\%)$ & & $685.46 \pm 23.25$ \\
\hline Fat binding capacity (\%) & & $523.76 \pm 15.65$ \\
\hline Solubility (\%) & & $86.79 \pm 0.03$ \\
\hline \multirow{4}{*}{ Color measurement } & $\mathrm{L}^{*}$ & $75.81 \pm 1.26$ \\
\hline & $a^{*}$ & $8.53 \pm 0.98$ \\
\hline & $b^{*}$ & $21.95 \pm 0.55$ \\
\hline & Whiteness & 66.25 \\
\hline Bulk density $(\mathrm{g} / \mathrm{mL})$ & & $0.19 \pm 0.002$ \\
\hline Particle size (nm) & & 1606 \\
\hline $\mathrm{pH}$ & & $6.99 \pm 0.11$ \\
\hline
\end{tabular}

Chitosan yield of $18.82 \%$ as determined in this study was higher than that reported by Varun et al. (2017) who obtained a yield of $12.03 \%$. On the other hand, the yield obtained in the present study was higher than that reported by Ait et al. (2018) who obtained a yield between $2.1 \%$ and 4.4\%. Kucukgulmez et al. (2011) extracted chitosan from Metapenaeus stebbingi shell waste 
and reported a yield of $17.48 \%$. Nessa et al. (2011) found that yield for chitosan extracted from prawn shell waste ranged from 16.4-19.6\%. The chitosan yield of pink shrimp shell used in the present study was higher than those obtained from some species by Varun et al. (2017) and Ait et al. (2018); however, it was comparable with those reported by Kucukgulmez et al. (2011) and Nessa et al. (2011). This high chitosan yield determined in this study may be due to the use of autoclave method in the deacetylation step. Sedaghat et al. (2017) compared three different (traditional, microwave, and autoclave) methods to obtain chitosan from shrimp shells and reported that the highest chitosan yield was obtained with the autoclave method. Hossain $\&$ Igbal (2014) reported that the low concentration of $\mathrm{HCl}$ used in demineralization steps could not remove minerals from shrimp shells. They also added that lower chitosan yield might be due to depolymerization of the chitosan polymer, loss of sample mass/weight from excessive removal of acetyl groups from the polymer during deacetylation, and loss of chitosan particles during washing. In addition, Samar et al. (2013) reported that yields of chitosan increased significantly by increasing the concentration of $\mathrm{NaOH}$ solution used in the deacetylation process. Similarly, Fatima (2020) reported that the yields of chitosan increased with decreasing the chitin particle size and increasing the concentration of $\mathrm{NaOH}$ solution used in deacetylation step. This variation in chitosan yield may be due to different shrimp species and different extraction methods (such as different sodium hydroxide ratio and deacetylation temperature etc.) used in deproteinization, demineralization, and deacetylation process. At the same time, these differences in chitosan yield may be associated with effectiveness in removing process of minerals and proteins attached to them.

Khan et al. (2002) explained that chitosan is hygroscopic in nature so it can be affected by moisture absorption during storage. Li et al. (1992) reported that commercial chitosan may contain <10\% moisture content. The moisture content of the shrimp shell chitosan samples was 3.65 $\pm 0.36 \%$. Kucukgulmez et al. (2017) reported that the moisture content of chitosan extracted from pink shrimp was between $1.52 \%$ and $1.80 \%$. Hossain \& Iqbal (2014) determined moisture content ranging from $7.69 \%$ to $8.25 \%$ for chitosan obtained from shrimp shell waste. Nessa et al. (2011) investigated that the moisture content of shrimp chitosan is ranging from $0.34 \%$ to $0.45 \%$. There are differences in the amount of moisture between the present study and the several studies. These differences are thought to be due to different processing protocols such as extraction temperatures, time, and drying conditions (Hossain \& Iqbal 2014).

The DD has a vital feature for chitosan as it affects the physical, chemical and biological properties, acid-base and electrostatic properties, biodegradability properties of chitosan ( $\mathrm{Li}$ et al. 1992). DD is an important parameter that determines the industrial quality of chitosan (Samar et al. 2013). Considering the importance of this parameter, Li et al. (1992) reported that the term chitosan should be used when the degree of deacetylation is above 70\%. Kumari et al. (2017) found the degree of deacetylation at 75\%,78\%, and 70\% for chitosan obtained from fish, shrimp, and crab, respectively. Hossain \& Iqbal (2014) extracted chitosanbased on different concentrations of $\mathrm{NaOH}$ treatment and found the degree of deacetylation between $45.50-81.24 \%$. In the present study, the DD of the extracted chitosan was found to be $81.50 \%$. Kucukgulmez et al. (2017) reported that the DD of chitosan extracted from pink shrimp was $72.86 \%$ in the low degree group and $93.70 \%$ in the high degree group. Sudatta et al. (2020) found that the deacetylation degree of chitosan from Pinna bicolor was 59.76\%. Mittal et al. (2021) found that the deacetylation degree of chitosan produced under various temperatures for different times ranged from $71.93 \%$ to $79.14 \%$. del Carmen BorjaUrzola et al. (2020) reported that deacetylation degrees of chitosan extracted based on with and without ultrasound-stir were $48.98 \%$ and $65.16 \%$, respectively.

Molecular weight is one of the most important factors that affect the physicochemical and functional properties of chitosan (Yen et al. 2009; Fernández-Martin et al. 2014). Biological and biomedical applications of chitosan are highly dependent on both the DD and the MW of the polymer (Abdou et al. 2008). In the present study, the MW was determined to be $310 \mathrm{kDa}$. This data was agreement with the Mw (161-451 kDa) of chitosan prepared from chitin with different treated conditions (Trung et al. 2020). A similar study performed by Kucukgulmez et al. (2011) reported the MW of $2.20 \mathrm{kDa}$ for chitosan obtained from Metapenaeus stebbingi shells while Samar et al. (2013) found the MW in the range from 866.03 to $4467.05 \mathrm{kDa}$ for chitosan obtained from shrimp shell wastes. Boudouaia et al. (2019) obtained two different types of chitosan from shrimp shells and found their MW as $354 \mathrm{kDa}$ and $412 \mathrm{kDa}$. Kumari et al. (2017) detected low MW (6.273 kDa) in chitosan from shrimp shells and reported that this may be due to low degree of deacetylation. The MW of chitosan extracted from shrimp shell wastes in the present study is not comparable to that reported in previous studies and the difference could be ascribed to several factors involved in the preparation of chitosan samples such as temperature, concentration of alkali and acid solutions, sources of chitosan, and treatments before chitosan.

WBC and FBC of chitosan extracted from shrimp shells wastes in the present study were found to be $685.46 \pm 23.25 \%$ and $523.76 \pm 15.65 \%$, respectively. And these results are consistent with the WBC $(712.99 \%)$ and FBC (531.15\%) data reported by Kucukgulmez et al. (2011). Similarly, Abirami et al. (2021) reported that the WBC and FBC for shrimp shells were 601.11\% and $441.07 \%$, respectively. Hossain \& Iqbal (2014) reported that WBC and FBC for shrimp chitosan were 537.29\% and 427.98\%, respectively. On the other hand, No et al. (2000) determined that the WBCs and FBCs values of six commercial chitosan samples ranged from $355 \%$ to $611 \%$ and $217 \%$ to $477 \%$, respectively. Cho et al. (1998) reported that the WBC and FBC for different commercial chitosan ranged from $458 \%$ to $805 \%$ and $314 \%$ to $535 \%$, respectively. In another study, Kumari et al. (2017) found lower WBC (358\%) and FBC (246\%) for shrimp chitosan, respectively. However, Mohanasrinivasan et al. (2014) determined higher WBC (1136\%) and FBC (772\%) for chitosan compared to the result of the present study. WBC and FBC basically depend 
on the demineralization and deproteinization procedure, but different chitosan sources are also important factors affecting this situation (Kumari et al. 2017).

Solubility is an important parameter for determining the quality of chitosan and factors such as deacetylation time, temperature, the concentration of $\mathrm{NaOH}$ solution, and particle size play a critical role in determining solubility (Hossain \& Iqbal 2014). Samar et al. (2013) obtained excellent solubility ranging from $83.28 \%$ to $99.05 \%$ by modulating particle size and concentration of $\mathrm{NaOH}$ solution. Hossain \& Iqbal (2014) determined the solubility of chitosan ranging from $48.3 \%$ to $97.65 \%$ at different $\mathrm{NaOH}$ concentrations. The solubility of chitosan extracted from shrimp shell wastes in this study was found to be $86.79 \pm 0.03 \%$, which is comparable with the values reported by Hossain \& Iqbal (2014) and Samar et al. (2013).

The colorimetric parameters $\mathrm{L}^{*}, \mathrm{a}^{*}, \mathrm{~b}^{*}$, and whiteness index of the chitosan samples are given in Table 1 . In the present study, the values of $\mathrm{L}^{*}, \mathrm{a}^{*}, \mathrm{~b}^{*}$, and whiteness index were determined to be 75.81, 8.53, 21.95, and 66.25, respectively. Based on visual observations, the color of chitosan samples ranged from white to light yellow. The L* value of the chitosan samples in this study is similar to that reported in previous studies (Alishahi et al. 2011; Kucukgulmez et al. 2011). The redness value (denoted by $\mathrm{a}^{*}$ ) of the extracted chitosan was of the highest intensity, which may have been due to contamination caused by the pigments present in chitin during the deacetylation process. While the $b^{*}$ value of chitosan obtained in this study was found to be comparable with the values of Kucukgulmez et al. (2011), it was found to be higher than that reported (10.1-13.65) by Alishahi et al. (2011). The whiteness index (66.25) determined in this study was found to be higher than those (35.78-43.30) of chitosan obtained from shrimp shell by Vallejo-Domínguez et al. (2021). They reported that this lower whiteness index may be due to the oxidization of samples during the sonication process.

In the present study, the bulk density of chitosan was found as $19 \mathrm{~g} / \mathrm{mL}$. Trung et al. (2006) determined that the bulk density of $75 \%, 87 \%$, and $96 \%$ deacetylation grade chitosan from shrimp shells were $0.59,0.54$, and $0.531 \mathrm{~g} / \mathrm{mL}$, respectively. No et al. (2000) found the bulk density of chitosan from six different sources as $0.18-0.33 \mathrm{~g} / \mathrm{mL}$. Rout (2001) reported that the bulk density decreased with increasing deacetylation degree. The results of the present study showed similarity with the data reported by No et al. (2000), but they were different from the data determined by Trung et al. (2006). This may be due to the porosity of the material before treatment.

In this study, the particle size of chitosan was found to be $1606 \mathrm{~nm}$. Similarly, Dananjaya et al. (2017) reported that particle size of chitosan was $1658 \mathrm{~nm}$. Kong et al. (2010) reviewed that decreasing particle size improved antibacterial activity. Also, Liu et al. (2018) reported that small particle size is preferred in drug delivery systems. Bough et al. (1978) reported that smaller particle size $(1 \mathrm{~mm})$ exhibited higher MW and viscosity than those with either 2 or $6.4 \mathrm{~mm}$ particle size.

The $\mathrm{pH}$ value of chitosan produced from pink shrimp shells was found to be 6.99 \pm 0.11 . Similarly, Paul et al. (2014) determined the $\mathrm{pH}$ value of chitosan from sea prawn (Fenneropenaeus indicus) as 6.7. The researchers reported that the $\mathrm{pH}$ value of chitosan from Panaeus monodon shell was 8.5 (Puvvada et al. 2012) and 8.0 (Divya et al. 2014). This is probably due to differences in experimental methods and chitosan characteristics.

The FT-IR spectra of the extracted chitosan samples are presented in Figure 2. The spectra showed peaks around 3256 to $3422 \mathrm{~cm}^{-1}$, indicating that the stretching vibration of $\mathrm{O}-\mathrm{H}$ and $\mathrm{N}-\mathrm{H}$ bands. The $1661 \mathrm{~cm}^{-1}$ peak in the spectra denotes the vibrations of the carbonyl group (amide band I). The peak at $1619 \mathrm{~cm}^{-1}$ shows N-H bending (amide II). Amide I and amide II are known as the characteristic bands for chitosan and were observed at around 1661 and $1619 \mathrm{~cm}^{-1}$. This characteristic band is commonly assigned to the stretching of the $\mathrm{CO}$ group hydrogen bonded to amide group of the neighboring intra-sheet chain (Al Sagheer et al. 2009). The band at $1153 \mathrm{~cm}^{-1}$ was assigned to amide III. For the $-\mathrm{CH}_{2}$ groups in $\mathrm{CH}_{2} \mathrm{OH}$, peaks spiked at 3103 and $1554 \mathrm{~cm}^{-}$ ${ }^{1}$ for the extracted chitosan samples. Oxygen stretching of glycosidic linkage was found to be $1062 \mathrm{~cm}^{-1}$. The C-O stretching of the structure was observed at 1008 and $950 \mathrm{~cm}^{-1}$. The $-\mathrm{CH}_{3}$ group of $\mathrm{NHCOCH}_{3}$ (amide bond) can be seen at $1376 \mathrm{~cm}^{-1}$. The pyranose ring was found at $895 \mathrm{~cm}^{-1}$. The FT-IR spectrophotometry results of the extracted chitosan samples used in the present study were confirmed with those of the previous studies (Kucukgulmez et al. 2011; Varun et al. 2017; Ibitoye et al. 2018). 


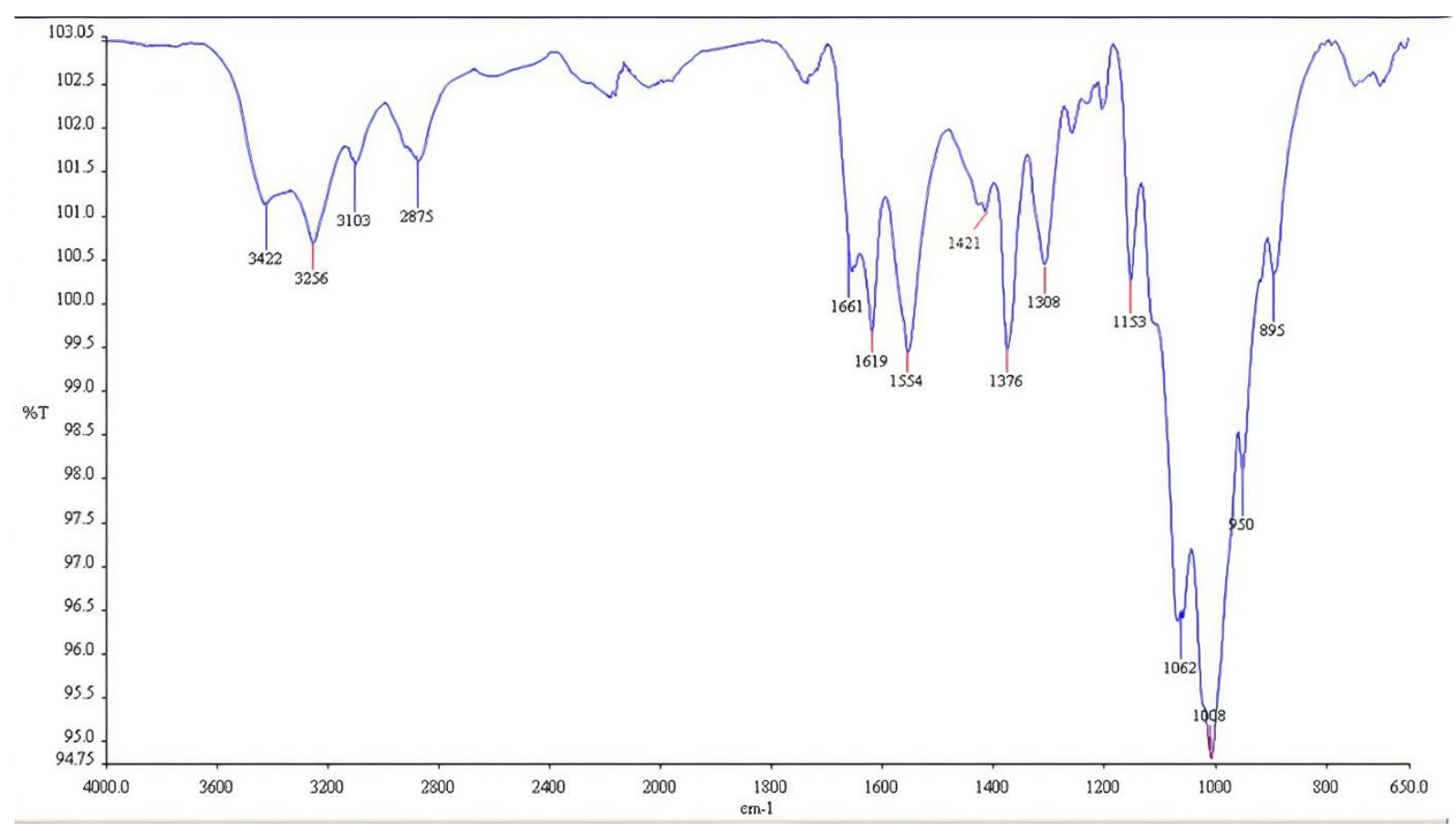

Figure 2- The FT-IR spectrum of extracted chitosan.

SEM analysis was performed to determine the molecular structure of the extracted chitosan (Fig. 3). A layer of flakes is obvious in Figures 3A and 3B, which is similar to that reported by Kucukgulmez et al. (2011). A fibrous structure with a rough surface including pores of chitosan derivatives can be distinguished in Figures 3C and 3D, which is similar to that reported by Hassan et al. (2018). Micropores of extracted chitosan derivatives can be seen clearly in Figures $3 \mathrm{E}$ and $3 \mathrm{~F}$. 

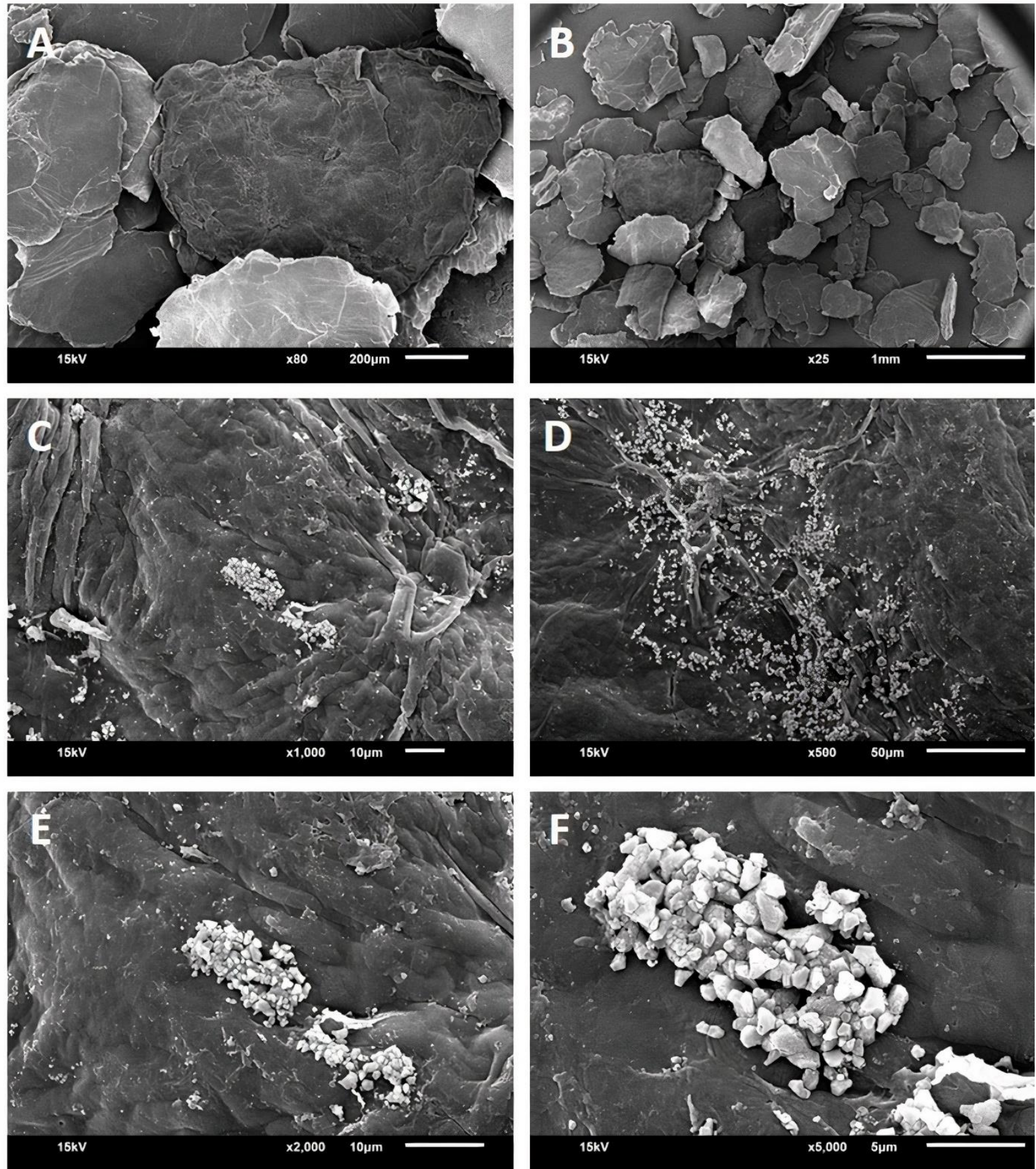

Figure 3- SEM micrographs of the extracted chitosan at (A) 80x (B) 25x (C) 1000x (D) 500x (E) 2000x (F) 5000x magnifications.

The TG, DTG, and DTA curves obtained by the thermal degradation of the extracted chitosan at a heating rate of $10^{\circ} \mathrm{C} \mathrm{min}-1$ are shown in Figure 4. The blue curve indicates TGA, the red one indicates DTA, and the green one indicates DTG. The initial temperature of weight loss (T0) is $250{ }^{\circ} \mathrm{C}$ (weight loss $8 \%$ ), the final temperature of weight loss (Tf) is $355^{\circ} \mathrm{C}$ (weight loss $60 \%$ ) and the temperature (Tp) at maximum weight loss rate is $340{ }^{\circ} \mathrm{C}$ (weight loss $43 \%$ ). The residual product is $40 \%$. Chitosan film lost almost all of its weight at $560{ }^{\circ} \mathrm{C}(92 \%)$. 


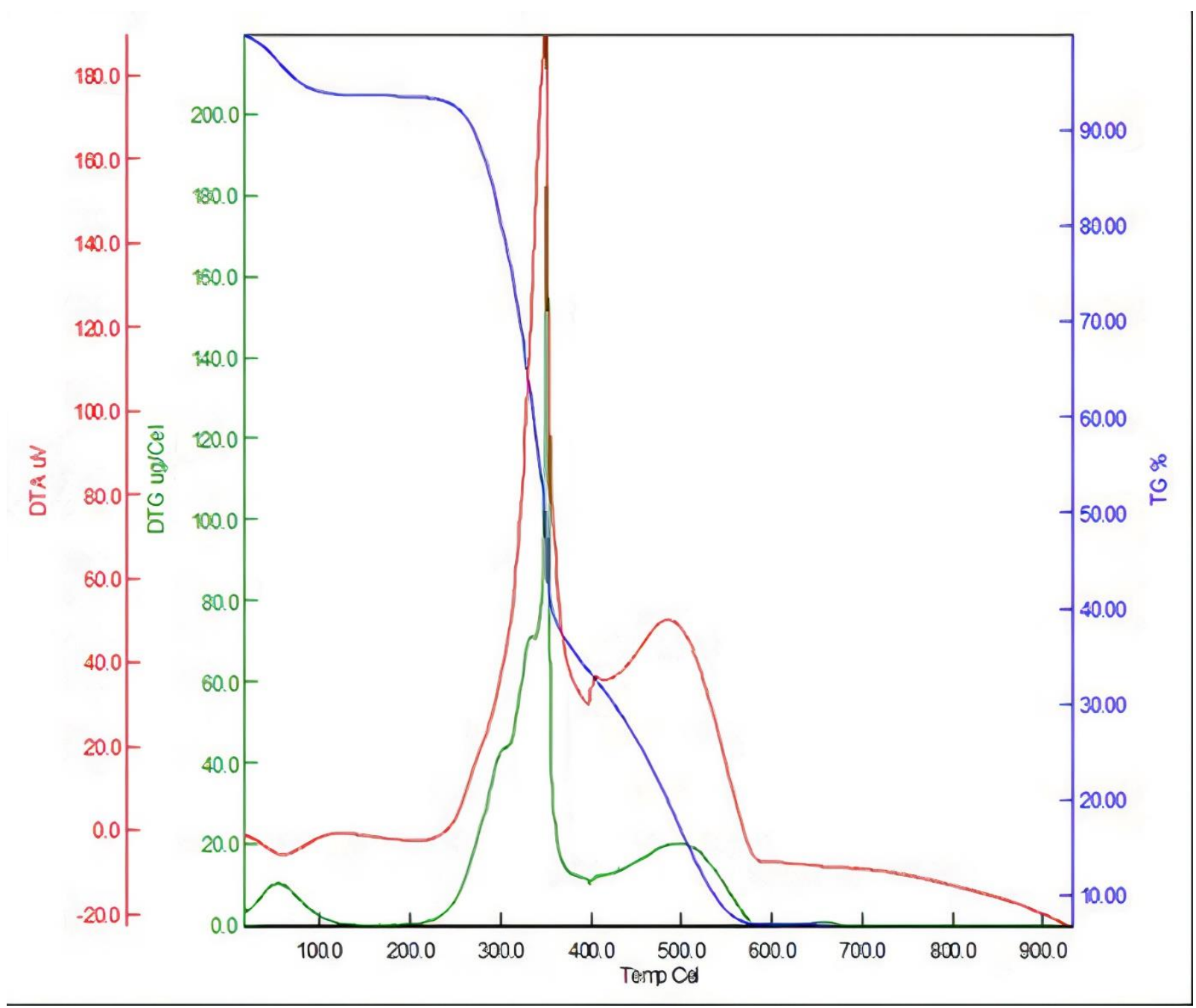

Figure 4- TGA, DTA, and DTG analyses of extracted chitosan

\section{Conclusions}

Waste recycling is a global concern and we believe that biowaste generated from the seafood industry such as shrimp shell wastes can be put to better use by extracting chitosan from such waste products and utilizing the same in a wide variety of applications such as in chemical, food processing, cosmetic, and biomedical and pharmaceutical industries. The physicochemical characteristics such as MW, DD, solubility, moisture, WBC, and FBC determined in the present study indicate that the quality of chitosan obtained from pink shrimp shell waste has the potential of being a high-quality source of chitosan for such applications. Therefore, further studies are recommended to understand the antimicrobial and antioxidant effect of the chitosan produced from pink shrimp shells.

\section{Acknowledgments}

The authors would like to thank Recep Tayyip Erdogan University the Faculty of Arts and Sciences (Department of Chemistry) for their contribution during analyses (FT-IR, SEM, TG, DTA, DTG).

\section{References}

Abdou E S, Nagy K S A \& Elsabee M Z (2008). Extraction and characterization of chitin and chitosan from local sources, Bioresources Technology 99: 1359-1367. https://doi.org/10.1016/j.biortech.2007.01.051

Abirami S, Nagarajan D, Antony V S, Mini Varsini A, Sugasini A \& Anand D A (2021) Extraction, characterization, and utilization of shrimp waste chitin derived chitosan in antimicrobial activity, seed germination, preservative, and microparticle formulation. Biointerface Research in Applied Chemistry 11(2): 8725-8739. https://doi.org/ 10.33263/BRIAC112.87258739

Ait B M, Chairi H, Laglaoui A, Arakrak A, Zantar S, Bakkali M \& Hassani M (2018). Optimization and characterization of gelatin and chitosan extracted from fish and shrimp waste. E3S Web of Conferences, 37, 02006. https://doi.org/10.1051/e3sconf/20183702006

Alishahi A, Mirvaghefi A, Tehrani M R, Farahmand H, Shojaosadati S A, Dorkoosh F A \& Elsabee M Z (2011). Enhancement and characterization of chitosan extraction from the wastes of shrimp packaging plants. Journal of Polymers and the Environment 19: 776-783. https://doi.org/10.1007/s10924-011-0321-5 
Al Sagheer F A, Al-Sughayer M A, Muslim S \& Elsabee M Z (2009). Extraction and characterization of chitin and chitosan from marine sources in Arabian Gulf. Carbohydrate Polymers 77(2): 410-419. https://doi.org/10.1016/j.carbpol.2009.01.032

Amiri E, Rahmaninia M \& Khosravani A (2019). Effect of chitosan molecular weight on the performance of chitosan-silica nanoparticle system in recycled pulp. BioResources 14(4): 7687-7701.

Amoo K O, Olafadehan O A \& Ajayi T O (2019). Optimization studies of chitin and chitosan production from Penaeus notialis shell waste. African Journal of Biotechnology 18(27): 670-688. https://doi.org/10.5897/AJB2019.16861

AOAC (1995). Official methods of analysis of AOAC International, 16th edition. Volume 2. 1995. AOAC (Association of Official Analytical Chemists) International; Arlington; USA.

Ben Seghir B \& Benhamza MH (2017). Preparation, optimization and characterization of chitosan polymer from shrimp shells. Journal of Food Measurement \&Characterization 11: 1137-1147. https://doi.org/10.1007/s11694-017-9490-9

Boudouaia N, Bengharez Z \& Jellali S (2019). Preparation and characterization of chitosan extracted from shrimp shells waste and chitosan film: application for Eriochrome black T removal from aqueous solutions. Applied Water Science, 9, 91. https://doi.org/10.1007/s13201019-0967-z

Bough W A, Salter W L, Wu A C M \& Perkins B E (1978). Influence of manufacturing variables on the characteristics and effectiveness of chitosan products. I. Chemical composition, viscosity, and molecular-weight distribution of chitosan products. Biotechnology and. Bioengineering 20: 1931-1943. https://doi.org/10.1002/bit.260201208

Byun S M, No H K, Hong J H, Lee S I \& Prinyawiwatkul W (2013). Comparison of physicochemical, binding, antioxidant and antibacterial properties of chitosans prepared from ground and entire crab leg shells. International Journal of Food Science \& Technology 48(1): 136142. https://doi.org/10.1111/j.1365-2621.2012.03169.x

Cho Y I, No H K \& Meyers S P (1998). Physicochemical characteristics and functional properties of various commercial chitin and chitosan products. Journal of Agricultural and Food Chemistry 46: 3839-3843. https://doi.org/10.1021/jf971047f

Dananjaya S H S, Erandani W K C U, Kim C H, Nikapitiya C, Lee J \& De Zoysa M (2017). Comparative study on antifungal activities of chitosan nanoparticles and chitosan silver nano composites against Fusarium oxysporum species complex. International journal of biological macromolecules 105: 478-488. https://doi.org/10.1016/j.ijbiomac.2017.07.056

Daraghmeh N H, Chowdhry B Z, Leharne S A, Al Omari M M \& Badwan AA (2011). Chitin. Profiles of Drug Substances, Excipients and Related Methodology 36: 35-102. https://doi.org/10.1016/B978-0-12-387667-6.00002-6

del Carmen Borja-Urzola A, García-Gómez R S, Flores R \& del Carmen Durán-Domínguez-de M (2020). Chitosan from shrimp residues with a saturated solution of calcium chloride in metanol and water. Carbohydrate Research, $497,108116$. https://doi.org/10.1016/j.carres.2020.108116

Divya K, Rebello S \& Jisha M S (2014). A simple and effective method for extraction of high purity chitosan from shrimp shell waste. In: Proceedings of the International Conference on Advances in Applied Science \& Environmental Engineering pp. 141-145. ASEE. https://doi.org/10.15224/978-1-63248-004-0-93

Domszya J G \& Roberts G A F (1985). Evaluation of infrared spectroscopic techniques for analyzing chitosan. Die Makromolekulare Chemie 186: 1671-1677. https://doi.org/10.1002/macp.1985.021860815

El Knidri H, Belaabed R, El Khalfaouy R, Laajeb A, Addaou A \& Lahsini A (2017). Physicochemical characterization of chitin and chitosan producted from Parapenaeus longirostris shrimp shell wastes. Journal of Materials and Environmental Sciences 8: 3648-3653

Fatima B (2020). Quantitative Analysis by IR: Determination of Chitin/Chitosan DD. Modern Spectroscopic Techniques and Applications 107 p. https://doi.org/10.5772/intechopen.89708

Fernández-Martín F, Arancibia M, López-Caballero E, Gómez-Guillén C, Montero P \& Fernández-García M (2014). Preparation and molecular characterization of chitosans obtained from shrimp (Litopenaeus vannamei) shells. Journal of Food Science 79: E1722-E1731. https://doi.org/10.1111/1750-3841.12572

Galed G, Diaz E, Goycoolea F M \& Heras A (2008). Influence of N-deacetylation conditions on chitosan production from $\alpha$-chitin. Natural Product Communications 3: 543-550. https://doi.org/10.1177/1934578x0800300414

Hao G, Hu Y, Shi L, Chen J, Cui A, Weng W \& Osako K (2021). Physicochemical characteristics of chitosan from swimming crab (Portunus trituberculatus) shells prepared by subcritical water pretreatment. Scientific Reports 11(1): 1-9. https://doi.org/10.1038/s41598-021-813180

Hassan M A, Omer A M, Abbas E, Baset W M A \& Tamer M T (2018). Preparation, physicochemical characterization and antimicrobial activities of novel two phenolic chitosan Schiff base derivatives. Scientific Reports 8: 11416. https://doi.org/10.1038/s41598-018-29650-w

Hong P Z, Li S D, Ou C Y, Li C P, Yang L \& Zhang C H (2007). Thermogravimetric analysis of chitosan. Journal of applied polymer science 105(2): 547-551

Hossain M \& Iqbal A (2014). Production and characterization of chitosan from shrimp waste. Journal of the Bangladesh Agricultural University 12: 153-160. https://doi.org/10.3329/jbau.v12i1.21405

Ibitoye E B, Lokman I H, Hezmee M N M, Goh Y M, Zuki A B Z \& Jimoh A A (2018). Extraction and physicochemical characterization of chitin and chitosan isolated from house cricket. Biomedical Materials (Bristol) 13(2018): 025009. https://doi.org/10.1088/1748605X/aa9dde

Karsli B, Caglak E, Li D, Rubio N K, Janes M \& Prinyawiwatkul W (2019). Inhibition of selected pathogens inoculated on the surface of catfish fillets by high molecular weight chitosan coating. International Journal of Food Science and Technology 54: 25-33. https://doi.org/10.1111/ijfs.13897

Khan T A, Peh K K \& Ch'ng H S (2002). Reporting degree of deacetylation values of chitosan: The influence of analytical methods. Journal of Pharmacy and Pharmaceutical Sciences 5: 205-212

Knoor D (1982). Functional properties of chitin and chitosan. Journal of Food Science 47: 593-595. https://doi.org/10.1111/j.13652621.1982.tb10131.x

Kong M, Chen X G, Xing K \& Park H J (2010). Antimicrobial properties of chitosan and mode of action: A state of the art review. International Journal of Food Microbiology 144: 51-63. https://doi.org/10.1016/j.ijfoodmicro.2010.09.012

Kucukgulmez A, Celik M, Yanar Y, Sen D, Polat H \& Kadak A E (2011). Physicochemical characterization of chitosan extracted from Metapenaeus stebbingi shells. Food Chemistry 126: 1144-1148. https://doi.org/10.1016/j.foodchem.2010.11.148

Kucukgulmez A, Kadak A E, Celik L, Farivar A \& Celik M (2017). Comparison of the physicochemical properties of chitosan extracted from shrimp shell waste with different deacetylation degrees. Feb-Fresenius Environmental Bulletin 26: 7750-7755 
Kumari S, Annamareddy S H K, Abanti S \& Rath P K (2017). Physicochemical properties and characterization of chitosan synthesized from fish scales, crab and shrimp shells. International Journal of Biological Macromolecules 104(B): 1697-1705. https://doi.org/10.1016/j.ijbiomac.2017.04.119

Li Q, Dunn E T, Grandmaison E W \& Goosen M F A (1992). Applications and properties of chitosan. Journal of Bioactive and Compatible Polymers 7: 370-397. https://doi.org/10.1177/088391159200700406

Metin C, Alparslan Y, Baygar T \& Baygar T (2019). Physicochemical, microstructural and thermal characterization of chitosan from blue crab shell waste and its bioactivity characteristics. Journal of Polymers and the Environment 27(11): 2552-2561. https://doi.org/10.1007/s10924-019-01539-3

Mittal A, Singh A, Aluko R E \& Benjakul S (2021). Pacific white shrimp (Litopenaeus vannamei) shell chitosan and the conjugate with epigallocatechin gallate: Antioxidative and antimicrobial activities. Journal of Food Biochemistry 45(1): e13569. https://doi.org/10.1111/jfbc.13569

Mohanasrinivasan V, Mishra M, Paliwal J S, Singh S K, Selvarajan E, Suganthi V \& Devi C S (2014). Studies on heavy metal removal efficiency and antibacterial activity of chitosan prepared from shrimp shell waste. 3 Biotech 4(2): 167-175. https://doi.org/10.1007/s13205013-0140-6

Mourya V K \& Inamdar N N (2008). Chitosan-modifications and applications: Opportunities galore. Reactive and Functional Polymers 68: 1013-1051. https://doi.org/10.1016/j.reactfunctpolym.2008.03.002

Nessa F, Masum S M, Asaduzzaman M, Roy S, Hossain M \& Jahan M (2011). A process for the preparation of chitin and chitosan from prawn shell waste. Bangladesh Journal of Scientific and Industrial Research 45: 323-330. https://doi.org/10.3329/bjsir.v45i4.7330

Nirmal N P, Santivarangkna C, Rajput M S \& Benjakul S (2020). Trends in shrimp processing waste utilization: An industrial prospective. Trends in Food Science \& Technology 103: 20-35. https://doi.org/10.1016/j.tifs.2020.07.001

No H K, Lee K S \& Meyers S P (2000). Correlation between physicochemical characteristics and binding capacities of chitosan products. Journal of Food Science 65: 1134-1137. https://doi.org/10.1111/j.1365-2621.2000.tb10252.x

No H K, Park N Y, Lee S H \& Meyers S P (2002). Antibacterial activity of chitosans and chitosan oligomers with different molecular weights. International Journal of Food Microbiology 74: 65-72. https://doi.org/10.1016/S0168-1605(01)00717-6

Paul S, Jayan A, Sasikumar C S \& Cherian S M (2014). Extraction and purification of chitosan from chitin isolated from sea prawn (Fenneropenaeus indicus). Asian Journal of Pharmaceutical and Clinical Research 7: 201-204

Puvvada Y, Vankayalapati S \&Sukhavasi S (2012). Extraction of chitin from chitosan from exoskeleton of shrimp for application in the pharmaceutical industry. International Current Pharmaceutical Journal 1: 258-263. https://doi.org/10.3329/icpj.v1i9.11616

Rinaudo M (2006). Chitin and chitosan: Properties and applications. Progress in Polymer Science 31: 603-632. https://doi.org/10.1016/j.progpolymsci.2006.06.001

Rout S K (2001). Physicochemical, functional and spectroscopic analysis of crawfish chitin and chitosan as affected by process modification. LSU Historical Dissertations and Theses. Louisiana State University, Baton Rouge, LA, USA. https://digitalcommons.lsu.edu/gradschool_disstheses/432

Samar M M, El-Kalyoubi M H, Khalaf M M \& Abd El-Razik M M (2013). Physicochemical, functional, antioxidant and antibacterial properties of chitosan extracted from shrimp wastes by microwave technique. Annals of Agricultural Sciences 58: 33-41. https://doi.org/10.1016/j.aoas.2013.01.006

Sedaghat F, Yousefzadi M, Toiserkani H \& Najafipour S (2017). Bioconversion of shrimp waste Penaeus merguiensis using lactic acid fermentation: An alternative procedure for chemical extraction of chitin and chitosan. International Journal of Biological Macromolecules 104: 883-888. https://doi.org/10.1016/j.ijbiomac.2017.06.099

Seo S, King J M \& Prinyawiwatkul W (2007). Simultaneous depolymerization and decolorization of chitosan by ozone treatment. Journal of Food Science 72: 522-526. https://doi.org/10.1111/j.1750-3841.2007.00563.x

Sudatta B P, Sugumar V, Varma R \& Nigariga P (2020). Extraction, characterization and antimicrobial activity of chitosan from pen shell, Pinna bicolor. International Journal of Biological Macromolecules 163: 423-430. https://doi.org/10.1016/j.ijbiomac.2020.06.291

Tokatlı K \& Demirdöven A (2018). Optimization of chitin and chitosan production from shrimp wastes and characterization. Journal of Food Processing and Preservation 42(2): e13494.

Trung T S, Thein-Han W W, Qui N T, Ng C H \& Stevens W F (2006). Functional characteristics of shrimp chitosan and its membranes as affected by the degree of deacetylation. Bioresource Technology 97: 659-663. https://doi.org/10.1016/j.biortech.2005.03.023

Trung T S, Tram L H, Van N V, Hoa N V, Minh N C, Loc P T \& Stevens W F (2020). Improved method for production of chitin and chitosan from shrimp shells. Carbohydrate Research 489, 107913. https://doi.org/10.1016/j.carres.2020.107913

TUIK (2020). Turkish Statistical Institute, Quantity of caught other sea fish (crustaceans, molluscs) in Turkey. http://www.tuik.gov.tr/Start.do, 2020 (accessed 28 July 2020) (In Turkish)

Vallejo-Domínguez D, Rubio-Rosas E, Aguila-Almanza E, Hernández-Cocoletzi H, Ramos-Cassellis M E, Luna-Guevara M L \& Show P L (2021). Ultrasound in the deproteinization process for chitin and chitosan production. Ultrasonics Sonochemistry, $72,105417$. https://doi.org/10.1016/j.ultsonch.2020.105417

Varun T K, Senani S, Jayapal N, Chikkerur J, Roy S, Tekulapally V B \& Kumar N (2017). Extraction of chitosan and its oligomers from shrimp shell waste, their characterization and antimicrobial effect. Veterinary World 10: 170-175. https://doi.org/10.14202/vetworld.2017.170-175

Yen M T, Yang J H \& Mau J L (2009). Physicochemical characterization of chitin and chitosan from crab shells. Carbohydrate Polymers 75: 15-21. https://doi.org/10.1016/j.carbpol.2008.06.006

(C) 2022 by the author(s). Published by Ankara University, Faculty of Agriculture, Ankara, Turkey. This is an Open Access article distributed under the terms and conditions of the Creative Commons Attribution (CC BY) license (http://creativecommons.org/licenses/by/4.0/), which permits unrestricted use, distribution, and reproduction in any medium, provided the original work is properly cited. 